\title{
Gestão de design para inovação social em um caso de economia
}

\section{solidária}

\section{Design management for social innovation in a case of solidarity economy}

\author{
Marco Antonio Weiss \\ Mestrando em Gestão de Design pela Universidade Federal de Santa Catarina (UFSC) - marcoweiss@outlook.com \\ Luiz Fernando Gonçalves de Figueiredo \\ Doutor em Engenharia de Produção pela Universidade Federal de Santa Catarina (UFSC). Professor da Universidade \\ Federal de Santa Catarina (UFSC) - Iff@cce.ufsc.br \\ Eugenio Andrés Díaz Merino \\ Doutor em Engenharia de Produção pela Universidade Federal de Santa Catarina (UFSC). Professor da Universidade \\ Federal de Santa Catarina (UFSC) - eugenio.merino@ufsc.br

\section{Giselle Schmidt Alves Díaz Merino} \\ Doutora em Engenharia de Produção pela Universidade Federal de Santa Catarina (UFSC). Professora da Universidade \\ do Estado de Santa Catarina (UDESC) e da Universidade Federal de Santa Catarina (UFSC) - gisellemerino@gmail.com
}

\section{Resumo}

O tema Inovação Social propõe novas soluções para os problemas sociais, afim de promover transformações sociais que beneficiam o coletivo. Sua relação com o cooperativismo e economia solidária é o foco deste estudo que busca responder como a gestão de design pode contribuir com os empreendimentos de economia solidária com vistas à inovação social. Objetiva realizar um diagnóstico preliminar, por meio da gestão de design, de um grupo de produtores veganos da região de Florianópolis/SC. Optou-se por pesquisa bibliográfica e estudo de caso, sob uma abordagem qualitativa de caráter exploratório com o intuito de aprofundamento da compreensão do grupo social estudado. Como resultado, foi possível mapear as potencialidades e fragilidades dos produtos artesanais veganos ofertados pelos empreendedores. Esse diagnóstico preliminar servirá de base para estratégias de gestão de design de modo a auxiliar os pequenos produtores veganos a melhor desenvolverem suas atividades, bem como na oferta de seus produtos e disseminação do conhecimento sobre o veganismo.

Palavras-chave: Gestão de Design. Inovação social. Economia solidária. Veganismo.

\begin{abstract}
The theme Social Innovation proposes new solutions to social problems in order to promote social transformations that benefit the collective. Its relation with cooperativism and solidarity economy is the focus of this study that seeks to answer how the management of design can contribute to the economics ventures with a view to social innovation. The objective is to carry out a preliminary diagnosis, through design management, of a group of vegan producers from the region of Florianópolis/SC. We chose a bibliographic research and case study, under a qualitative exploratory approach with the purpose of deepening the understanding of the social group studied. As a result, it was possible to map the potentialities and fragilities of the vegan artisanal products offered by the entrepreneurs. This preliminary diagnosis will serve as a basis for design management strategies to assist smallscale vegan producers to better develop their activities, as well as to offer their products and disseminate knowledge about veganism.
\end{abstract}

Keywords: Design management. Social innovation. Solidarity economy. Veganism.

Recebido em: 08/08/2018

Aceito em: 05/11/2018 


\section{INTRODUÇÃO}

Atualmente, o tema inovação social é abordado com frequência, devido a recorrente busca dos indivíduos por alternativas ao modelo de valores e estruturas sociais contemporâneas, os quais objetivam a geração de lucro e consumo de bens materiais.

A ideia que as pessoas têm hoje sobre bem-estar, bem como suas expectativas para sentirse bem, está associada a uma crescente oferta de produtos e serviços (MANZINI, 2008). Nessa busca por suprir a carência de bem-estar baseado em bens materiais, os recursos naturais, renováveis ou não, são degradados de forma insustentável. Nesse sentido, a ideia de inovação social envolve novas soluções para as relações sociais, trabalho e fonte de renda para melhorar as condições de vida, soluções essas que buscam a sustentabilidade por meio de novas práticas e conceitos.

Na esfera social e econômica, essas considerações se conectam com as do cooperativismo em que os participantes cooperam entre si ao invés de competir. De modo mais específico, estas se relacionam com o conceito de economia solidária, modelo econômico voltado para a produção, consumo e comercialização de bens e serviços de modo autogerido, igualitário e cooperativo entre seus membros. Assim, gera oportunidades de trabalho e renda aos seus integrantes. Para Arcanjo e Marques (2012, p. 7), a economia solidária apresenta diferentes formas "de produzir, vender, comprar e trocar o que é preciso para viver. Sem explorar os outros, sem querer levar vantagem, sem destruir o ambiente". Dessa forma, os empreendimentos de economia solidária têm base cooperativista e associativista, centrada na valorização do ser humano e não do capital. O autor prossegue ao dizer que, por meio da cooperação o grupo se fortalece mantendo o pensamento no bem coletivo e no próprio bem.

A escolha dos temas propostos é corroborada com um estudo de caso de um grupo de pequenos empreendimentos de produção e comércio de alimentos veganos ${ }^{1}$ que atuam de forma colaborativa e solidária na região de Florianópolis/SC - a proposta do veganismo se relaciona com o conceito de sustentabilidade, de forma que seu fundamento principal caracteriza-se pela eliminação da exploração animal em qualquer forma, seja na alimentação, no vestuário, em testes de medicamentos, cosméticos etc., na composição de produtos, no trabalho, no entretenimento e

\footnotetext{
${ }^{1}$ Optou-se por manter o anonimato dos produtores nessa pesquisa.
} 
no comércio (SOCIEDADE VEGANA, 2011). No contexto geral, os produtores veganos são, em sua maioria, pequenos empreendimentos, geralmente de estrutura familiar, que trabalham de forma caseira ou até mesmo na informalidade, como alternativa para vencer o desemprego e também para difundir esse estilo de vida mais saudável e sustentável.

O pressuposto do veganismo vem possui cada vez mais simpatizantes. Segundo a Mercy for Animals, uma organização não governamental dedicada à causa animal, o número de pessoas que diminuiriam o consumo de carne ou a substituíram completamente por alimentos vegetais tem crescido significativamente. Nos Estados Unidos o consumo de carne diminuiu $10 \%$ nos últimos 10 anos (ANDA, 2016).

Essa pesquisa propõe um estudo alinhado com as premissas de inovação social e economia solidária e busca responder ao seguinte problema: como a gestão de design pode contribuir com os empreendimentos de economia solidária com vistas à inovação social?

Para tanto, esta pesquisa tem como objetivo geral realizar um diagnóstico preliminar, por meio da gestão de design, de um grupo de produtores veganos da região de Florianópolis/SC. E especificamente:

- Aprofundar o conhecimento sobre os temas pesquisados;

- Realizar uma observação sistemática da organização;

- Associar os temas estudados ao grupo da pesquisa;

- Identificar as potencialidades e fragilidades da organização.

Figura 1 - Estrutura da pesquisa.

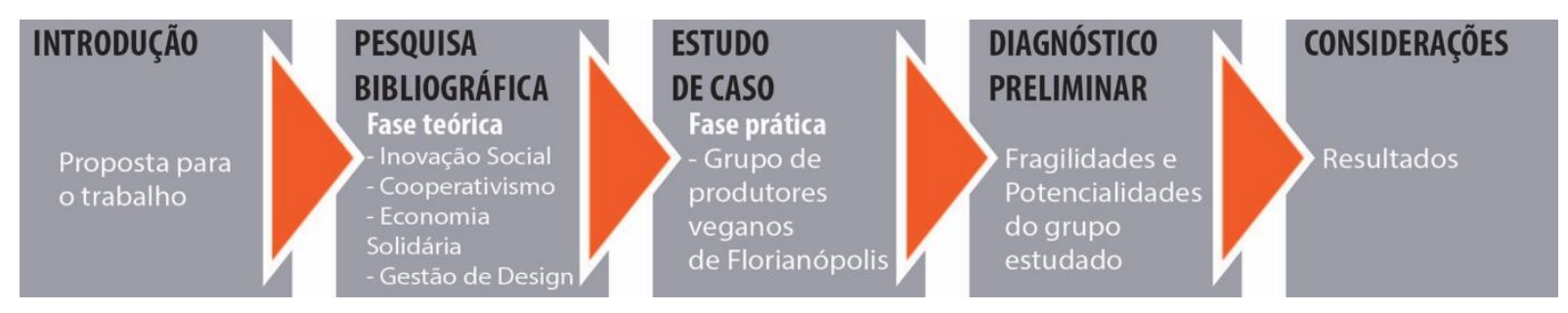

Fonte: elaborado pelos autores.

A estrutura desta pesquisa está esquematizada na figura 1 e segue a seguinte ordem: primeiro é apresentada esta introdução, a qual explana sobre o tema proposto; a segunda etapa se caracteriza como teórica, contando com a pesquisa bibliográfica que envolve os assuntos inovação 
social, cooperativismo, economia solidária e gestão de design; a terceira etapa, a fase prática da pesquisa, expõe sobre o estudo de caso e o diagnóstico da organização sob o foco da gestão de design com os resultados obtidos no levantamento de campo; e, por fim, as considerações finais da pesquisa.

\section{PROCEDIMENTOS METODOLÓGICOS}

Este item aborda o percurso teórico-metodológico seguido para se alcançar o objetivo proposto para esse estudo de construção do diagnóstico preliminar. A metodologia utilizada é de natureza qualitativa e centra-se na compreensão e explicação da dinâmica do grupo observado. Quanto ao objetivo, se caracteriza como pesquisa exploratória, que busca "considerar os mais variados aspectos relativos ao fato ou fenômeno estudado" (GIL, 2010, p. 27) a fim de levantar informações que darão continuidade a um trabalho com o grupo de produtores veganos de Florianópolis/SC.

Ainda, a pesquisa se classifica como aplicada, por meio de estudo de caso, o que de acordo com Gil (2010), pesquisas desse tipo são voltadas para aquisição de conhecimentos por meio de aplicação em uma situação específica, diante disso estão inseridos estudos que têm como finalidade resolver problemas constatados no contexto da sociedade em que os pesquisadores estão inseridos. Dessa forma, o grupo abordado nesse estudo foi escolhido por atuar no âmbito da universidade a qual os pesquisadores estão vinculados, de modo que o conhecimento construído na universidade possa ser difundido primeiro no contexto local.

O trabalho foi dividido em duas etapas. Na fase de construção do referencial teórico, foi realizado um levantamento bibliográfico para conceituar os termos inovação social, economia solidária, cooperativismo e gestão de design a fim de sustentar a construção do diagnóstico preliminar. Na segunda etapa, a aplicada, foi realizado o estudo de caso com o grupo de produtores veganos, dividida em três passos: observação, entrevista e construção do modelo de negócios Canvas. Nesse momento, foi realizando um levantamento de dados da situação atual e aprofundamento sobre a organização foco do estudo de caso por meio de observação aberta e entrevistas com os participantes do grupo de produtores. O quadro 1 apresenta as etapas do desenvolvimento desta pesquisa. 
Marco Antonio Weiss, Luiz Fernando Gonçalves de Figueiredo, Eugenio Andrés Díaz Merino, Giselle Schmidt Alves Díaz Merino

Quadro 1 - Estrutura da pesquisa.

\begin{tabular}{|l|l|l|}
\hline \multicolumn{2}{|c|}{ O quê? } & \multicolumn{1}{|c|}{ Como? } \\
\hline Etapa 1 & $\begin{array}{l}\text { TEÓRICA } \\
\text { (Fundam. teórica/Referências) }\end{array}$ & $\begin{array}{l}\text { Levantamento em livros, BDTD e publicações dos } \\
\text { últimos } 5 \text { anos }\end{array}$ \\
\hline Etapa 2 & $\begin{array}{l}\text { APLICADA } \\
\text { (Estudo de caso) }\end{array}$ & $\begin{array}{l}\text { 1. OBSERVAÇÃO: Aproximação do grupo de } \\
\text { produtores veganos para um panorama preliminar. } \\
\text { 2. ENTREVISTA: Compreender a estrutura } \\
\text { organizacional e obter informações sobre os produtos } \\
\text { e processos. } \\
\text { Questões divididas em 3 grupos: } \\
\text { *Organização *Pessoas *Produtos } \\
\text { 3. CANVAS: Estruturar o modelo de negócio. }\end{array}$ \\
\hline
\end{tabular}

Fonte: elaborado pelos autores.

Após o levantamento bibliográfico realizado no referencial teórico, fez-se uso de observação aberta e entrevista como técnicas de coleta de dados em campo. Fialho, Braviano e Santos (2005) explicam que a técnica de observação é utilizada a fim de avaliar o espaço de trabalho, bem como o comportamento do usuário e, como no caso dessa pesquisa, a observação aberta, geralmente se insere no início da análise, a fim de se traçar um panorama preliminar da situação. Já a técnica de entrevista, "por ser uma abordagem mais aprofundada, permite compreender alguns dos comportamentos dos usuários que não podem ser explicados de forma objetiva através do uso exclusivo das observações" (FIALHO; BRAVIANO; SANTOS, 2005, p. 71).

O primeiro contato formalizado com o grupo de produtores foi uma visita para apresentar a intenção dessa pesquisa e verificar o interesse de participação dos integrantes. Feito isso, foi agendada uma data para a realização do primeiro passo da etapa aplicada com a técnica de observação aberta, onde pode-se acompanhar a rotina do grupo no ambiente de trabalho, conhecer os produtos ofertados, especialmente para analisar a forma como o produto é disponibilizado no ponto venda e como se dá o atendimento ao público.

No passo seguinte, por meio de uma entrevista estruturada, os representantes dos quatro empreendimentos que compõe o grupo de produtores veganos foram indagados individualmente para captar informações e percepções das partes sobre o todo e chegar a um melhor entendimento de como se dá a organização e o relacionamento dentro do grupo. A entrevista foi dividida em três blocos de perguntas: organização - história do grupo, estrutura organizacional e gestão; pessoas - 
participantes envolvidos, relacionamento com clientes, fornecedores e produtos - portfólio de produtos, produção e comercialização. Cada entrevistado respondeu de acordo com a sua visão sobre o grupo e sobre o empreendimento que representa.

Por fim, com a análise dos dados obtidos, partiu-se para elaboração de um diagnóstico preliminar, com finalidade de identificar os pontos fortes e fracos da organização. Os resultados do levantamento de dados estão apresentados no estudo de caso do capítulo 4.

Quadro 2 - Descrição dos campos do Canvas.

\begin{tabular}{|c|c|c|}
\hline \multicolumn{2}{|r|}{ Campo } & Descrição \\
\hline O que? & Proposta de Valor & Produtos e serviços que criam valor no negócio \\
\hline \multirow{3}{*}{$\begin{array}{l}\text { Para } \\
\text { quem? }\end{array}$} & Segmentos de Mercado & $\begin{array}{l}\text { Pessoas para quem será ofertada a Proposta de } \\
\text { valor }\end{array}$ \\
\hline & $\begin{array}{l}\text { Relacionamento com o } \\
\text { Cliente }\end{array}$ & $\begin{array}{l}\text { A forma como se dará o relacionamento entre a } \\
\text { organização e os clientes }\end{array}$ \\
\hline & Canais de Relacionamento & $\begin{array}{l}\text { O meio pelo qual se dará o relacionamento com os } \\
\text { clientes }\end{array}$ \\
\hline \multirow{3}{*}{ Como? } & Parceiros & Principais fornecedores e parceiros \\
\hline & Atividades & $\begin{array}{l}\text { Ações necessárias para se colocar em prática a } \\
\text { Proposta de valor }\end{array}$ \\
\hline & Recursos & $\begin{array}{l}\text { Organização das principais atividades e recursos } \\
\text { para o negócio }\end{array}$ \\
\hline \multirow{2}{*}{ Quanto? } & Estrutura de Custos & Custos envolvidos na realização da Proposta de valor \\
\hline & Fontes de Renda & Como será o retorno financeiro \\
\hline
\end{tabular}

Fonte: Adaptado de Osterwalder (2011).

Após a coleta a análise dos dados em campo com os integrantes da organização, foi aplicada a ferramenta do modelo de negócios Canvas, este modelo se utiliza de um quadro para representar, visualizar, avaliar e definir um negócio. Segundo Osterwalder (2011), a proposta da ferramenta é que os campos do quadro sejam preenchidos com post-its pelos participantes, contribuindo com ideias para a definição desses componentes. A relevância do modelo Canvas se dá na sua contribuição para os processos de cocriação na concepção de novas ideias. O quadro 2 apresenta a descrição dos nove campos preenchidos no Canvas, subdivididos em quatro categorias: o quê?, se refere ao que será desenvolvido no negócio; para quem?, diz respeito às pessoas 
envolvidas no processo; como?, busca responder como o trabalho será realizado; e quanto?, fala sobre os custos e retorno financeiro esperado com o negócio.

O modelo Canvas foi utilizado para que o grupo do estudo de caso pudesse visualizar e ter mais clareza sobre o negócio ao qual pertencem, os produtos que ofertam, seus clientes, os processos envolvidos, bem como a estrutura de custos. A ferramenta foi aplicada uma semana após as entrevistas para que os integrantes tivessem um tempo para refletir sobre os assuntos levantados. Assim, as definições dos componentes do quadro surgiram das colocações dos integrantes com a mediação do pesquisador.

Os resultados obtidos nas etapas 1 e 2 desta pesquisa, com base nos procedimentos metodológicos aqui detalhados, são apresentados a seguir, finalizando com a análise e discussão dos mesmos.

\section{REFERÊNCIAL TEÓRICO (ETAPA 1)}

\subsection{INOVAÇÃO SOCIAL}

Segundo Manzini (2008), o termo inovação social diz respeito aos novos modos como os indivíduos ou comunidades atuam para resolver seus problemas ou criar novas oportunidades. Tais inovações são conduzidas, principalmente, por mudanças de comportamento, mais do que por mudanças tecnológicas ou de mercado. A inovação social relaciona como o desenvolvimento de novos produtos, processos e serviços que geram a inclusão social, trabalho e renda além de melhor a qualidade de vida das pessoas envolvidas. (SOARES, 2014).

O Centro para Inovação Social (CSI, 2017), da Stanford Graduate School of Business, conceitua inovação social como uma solução inovadora para um problema social mais eficaz, eficiente, sustentável do que soluções atuais. O valor criado é para a sociedade e não somente para particulares. A inovação social concentra a atenção nas ideias e soluções que criam valor social bem como nos processos por meio dos quais são gerados, não apenas em indivíduos e organizações.

Os atores da inovação social, para Maurer (2011), aprendem novos conhecimentos e habilidades por meio de um intercâmbio de informações e de formação, o que leva à geração de novas regras e de novos padrões sociais. Nesse sentido, Manzini (2008), insere no contexto de inovação social as comunidades criativas, as quais aplicam sua criatividade para quebrar os 
modelos dominantes de pensar e fazer e, assim, geram as descontinuidades locais. Elas resultam de uma original combinação de demandas e oportunidades.

Sejam sítios ou comunidades criativas, os agrupamentos de pessoas e das relações que se estabelecem entre eles formam sistemas dinâmicos, que como organismos vivos adequamse aos movimentos internos e externos de suas organizações, permitindo a iniciativa, ação e expressão de capacidades de seus atores sociais. Portanto, é possível observar um novo tipo de conceito de bem-estar que emerge associado à prática ativa de atores sociais e à possibilidade de expressão de suas capacidades: o bem-estar ativo (PRESTES; FIGUEIREDO, 2011, p. 39).

Segundo Manzini (2008, p. 68), uma comunidade criativa quando se consolida, "torna-se um empreendimento social difuso, produzindo tanto resultados específicos quanto qualidade social". O autor prossegue dizendo que a especificidade desses empreendimentos está em estender o conceito de "social", de forma que os indivíduos passam a enfrentar juntos as dificuldades comuns da vida cotidiana, assim como atender às suas decorrentes novas demandas de bem-estar.

Prestes e Figueiredo (2011) comentam sobre uma mudança no entendimento de bemestar, antes focado no consumo crescente de produtos, para um bem-estar que considera a qualidade do contexto de vida das pessoas, de modo que essas possam expressar suas identidades e tomar suas próprias decisões. Esse novo conceito de bem-estar corresponde com uma realidade sustentável. "Em paralelo, um novo tipo de design cresce, com o intuito de estimular produções locais, resgatar práticas culturais, fortalecer relacionamentos humanos e encorajar os indivíduos a serem valorizados como atores sociais" (PRESTES; FIGUEIREDO, 2011, p. 40).

Moulaert, Martinelli, Swyngedouw e González (2005), dizem que existem dois tipos de iniciativas inerentes à inovação social. A primeira é fundamentada nas formas inovadoras de suprir as necessidades de um indivíduo ou grupo, de forma que uma crise e sua consequente recuperação podem acelerar a inovação social. A segunda perspectiva se baseia na inovação social das relações sociais entre a comunidade e o poder local. Para o autor, a junção das duas vertentes potencia o desenvolvimento local, visto como uma alternativa à lógica capitalista, ao buscar formas alternativas como a solidariedade e reciprocidade entre a comunidade (apud SOARES, 2014).

Nessa perspectiva, Manzini (2008) traz o conceito de organizações colaborativas, de forma que estas propõem soluções para atender aos interesses privados, sociais e ambientais. Por fim, 
define que estas são formas de organização em que todos são participantes ativos e, assim, as distinções entre papéis de produtor e de usuário/consumidor se diluem.

\subsection{COOPERATIVISMO E ECONOMIA SOLIDÁRIA}

O cooperativismo, segundo Gaiger (2013), foi introduzido no Brasil no final do século XIX, como estratégia dos imigrantes europeus, principalmente nas regiões sul e sudeste, para superar as situações de evidente desamparo em que viviam. Nesta época, surgiram as cooperativas de consumo, de crédito e agropecuárias, localizadas principalmente no Rio Grande do Sul, em São Paulo e Rio de Janeiro.

A Organização das Cooperativas Brasileiras (OCB, 2017) define o cooperativismo como uma filosofia de vida, mais que um modelo de negócios, com a finalidade de transformar o mundo em um lugar mais justo, feliz, equilibrado e com melhores oportunidades para todos, ou seja, "em uma cooperativa, o que tem mais valor são as pessoas e quem dita as regras é o grupo. Todos constroem e ganham juntos".

O cooperativismo possui um papel de inclusão social, econômica e cultural para o desenvolvimento sustentável. Baseando-se na união de pessoas, este modelo se caracteriza pela participação democrática, independência e autonomia. Tem como objetivo promover o desenvolvimento econômico e o bem-estar social de todos os seus cooperados, bem como da comunidade em que se inserem. As decisões são tomadas de forma coletiva e os resultados obtidos são distribuídos justa e igualitariamente, conforme a participação de cada membro. A geração de renda e a inserção social são alcançadas por meio da distribuição dos resultados das cooperativas entre todos os cooperados. Atuam através da autogestão, de forma democrática, os quais seus membros participam ativamente na tomada de decisões e na formulação das políticas da organização (MOTTA, 2017).

Dessa forma, Arcanjo e Marques (2012) esclarecem que o cooperativismo se apresenta como uma das soluções para o problema do desemprego e da exclusão social. Por meio da cooperação, propicia o empreendedorismo, o desenvolvimento econômico e a melhoria da qualidade de vida das pessoas.

Motta (2017) diz que, por partir da união de pessoas com foco no crescimento conjunto, as cooperativas contribuem com o desenvolvimento sustentável. Apresentam um modelo econômico, 
social, cultural e ambiental equilibrado para satisfazer as necessidades das gerações atuais, sem comprometer a capacidade das gerações futuras.

\begin{abstract}
o desenvolvimento sustentável não ocorre a partir do esforço de apenas um ator social, mas se dá por meio de suas inter-relações com os demais atores. [...] a partir do conceito de valor sustentável disseminado aos seus stakeholders, as empresas que condizem ao empreendedorismo sustentável, buscam criar, compartilhar ou mesmo introduzir tais valores a esses interessados (ORSIOLLI; NOBRE, 2016, p. 518).
\end{abstract}

Segundo Motta (2017, p. 14), as cooperativas têm contribuído significativamente para a inclusão social, "o número de associados a cooperativas representa 6,3\% da população brasileira. Se somadas, as famílias dos cooperados, estima-se que hoje o movimento agregue mais de 52 milhões de pessoas, ou $25,4 \%$ do total de brasileiros".

A partir disso, o termo economia solidária ganhou expressão no Brasil. Segundo Gainer (2013), ao longo dos anos de 1990, conforme as iniciativas econômicas apareceram no país, ganhando reconhecimento por sua natureza associativa e suas práticas de cooperação e autogestão, a economia solidária se destacou por abranger categorias sociais e modalidades diversas de organização, tais quais unidades informais de geração de renda, associações de produtores e consumidores, sistemas locais de troca, comunidades produtivas autóctones e cooperativas dedicadas à produção de bens, à prestação de serviços, à comercialização e ao crédito. "As cooperativas solidárias destinam-se muitas vezes a sustentar atividades produtivas individuais ou familiares dos cooperados" (GAINER, 2013, p. 218).

Para Arcanjo e Marques (2012) a economia solidária pode ser entendida como uma forma de produção, consumo e distribuição de riqueza, que prioriza a valorização do ser humano e não do capital. Sua base associativista e cooperativista visa a produção, o consumo e a comercialização de bens e serviços de por meio da autogestão e igualdade entre os membros. Os autores afiançam que o público de empreendimentos de economia solidária são as pessoas excluídas pelo sistema capitalista, seja por idade, grau de instrução, falta de oportunidades, ou qualquer outro fator limitante.

De acordo com Gainer (2013), o trabalho em uma economia solidária passa a ter um valor simbólico, fundado na experiência de justiça e equidade. E traz ainda a satisfação de ser 
coproprietário e gestor do negócio, ter poder de decisão em prol do coletivo e de si e ressalva o sentimento de ser algo edificante e dignificante.

Singer (2002, p. 9) defende que para termos uma sociedade igualitária, a economia deveria ser solidária em vez de competitiva e assim "os participantes na atividade econômica deveriam cooperar entre si em vez de competir". Cada membro participa na atividade onde tem mais habilidade, gerando assim um produto e este, por fim, só tem utilidade no contexto geral, complementado pelos resultados das atividades dos demais membros. Dessa forma, a economia solidária se apresenta como uma proposta de trabalho autogerido e tem como principal característica a igualdade de direitos conquistada mediante a transparência da gestão, da divisão de poder e do desenvolvimento de tarefas com participação ativa dos sócio-trabalhadores.

O sucesso dessas organizações está relacionado com sua visão empreendedora e solidária, podendo ser ponderado pela "busca de resultados por meio de ação planejada e da otimização dos fatores produtivos, humanos e materiais". Desse modo, "a cooperação funciona como vetor da racionalização econômica, produzindo efeitos tangíveis e vantagens reais diante da ação individual e da cooperação não solidária". Assim, o trabalho cooperativo e a gestão coletiva permitem que "tais iniciativas se tornem superiores ao trabalho artesanal e individualizado dos pequenos produtores, mais produtivas do que as empresas convencionais e, sobretudo, mais recompensadoras do que a condição assalariada" (GAINER, 2013, p. 219).

Os empreendimentos de economia solidária possuem uma configuração de empresas autogestionárias, onde os associados decidem em conjunto as questões políticas, produtivas e estratégicas do empreendimento, assegurando os princípios cooperativistas dentro de um mercado capitalista. Para tanto, atividades educativas e o incentivo ao trabalho em grupo são base para o desenvolvimento de empresas com autogestão, de modo que os sócio-trabalhadores tenham a capacidade e conhecimento necessário na tomada de decisões no empreendimento, tais como metas de produção, políticas de investimentos e modernização (SILVA; FARIAS, 2014).

A seguir, a pesquisa abordará o tema gestão de design, em busca de elucidar a forma a qual tais empreendimentos podem lançar mão da ação planejada e da otimização dos fatores produtivos, humanos e materiais citados no texto.

\subsection{GESTÃO DO DESIGN}


A gestão de design busca uma forma de integração entre o design e meio empresarial, dessa forma, Preto e Alano (2013, p. 12) esclarecem que "o design junto de sua gestão tem a preocupação de comunicar e criar condições para que o seu público entenda sua mensagem e perceba seus benefícios, por meio de estratégias e estudos multidisciplinares".

Lauro (2014, p. 42) define a gestão de design como uma forma de "compreender e organizar as diferentes funções de design na empresa, integrando seus processos, ideias e projetos além de trabalhar para que exista uma cultura de design em todos os setores da empresa em seus três níveis: estratégico, tático/ funcional e operacional".

Segundo Mozota (2011), a gestão estratégica do design deve relacionar o design, estratégia, identidade e a cultura da empresa com o objetivo de inserir o design no processo da formulação estratégica da organização.

Best (2006, p. 16) faz um resumo de como a Gestão de Design pode interferir e colaborar interna e externamente ao sistema que envolve a organização. De acordo com a autora, dentro da organização, a Gestão de Design está presente nas comunicações da marca, no design dos produtos e dos serviços, no edifício corporativo e no ambiente do varejo, nos websites e nas campanhas publicitárias. Externamente, a Gestão de Design pode responder à crescente pressão sofrida pelas organizações em atender legislações, regulamentos e políticas governamentais, além de mudar atitudes ao redor do mundo em relação à gestão local e global de recursos (apud LAURO, 2014, p. 43).

Mozota (2011) diz que o gestor de design precisa ter o domínio do know-how de concepção por dois motivos principais, para a construção da realidade, que diz respeito ao relacionamento da empresa com o seu ambiente e, para compreender melhor as situações complexas na gestão estratégica por meio do domínio das habilidades de design. Dessa forma, tanto na gestão estratégica, como no processo de desenvolvimento de produtos, "o design é uma atividade de resolução de problemas, um exercício criativo, sistemático e de coordenação" (MOZOTA, 2011, p. 17).

Martins e Merino (2011, p. 71-72) explicam que o design possui um papel social na transformação da sociedade por meio da materialização de uma ideia no desenvolvimento de estratégias que permitem difundir conhecimento e nesse contexto, dizem ainda que "na busca por uma consciência coletiva o processo de criação visa otimizar performance, inovação, qualidade, 
durabilidade, aparência e custos referentes a cada produto, ambiente, informação e marca". Entende-se então, de acordo com Lauro (2014, p. 51), que

\begin{abstract}
A Gestão de Design deve, então, estar presente na organização desde a concepção de ideias e estratégias de produtos, ações, processos e projetos; passando pelo planejamento de todo o ciclo de vida dos produtos, pela comunicação interna e externa da marca em meios tangíveis, por meio de um sistema de identidade visual, e intangíveis, por meio de atitudes.
\end{abstract}

Contribuindo ao contexto desta pesquisa, Silva, Triska, Merino e Merino (2017) explicitam que a gestão de design mostra sua importância na construção de uma tecnologia social, em que o design aparece como um resultado tangível, sendo a ponta do processo. Especificamente em um grupo que trabalha com produtos artesanais, o design pode contribuir oferecendo um sistema produtivo mais eficiente, aliando o saber-fazer local e as características produtivas às necessidades do mercado formal. Segundo os autores supracitados, sem oferecer um produto competitivo em estética e funcionalidade, de nada adianta um processo produtivo solidário, da mesma forma que não se terá um produto competitivo sem uma identidade de marca que diferencia, valide e sustente o produto, bem como a empresa que o oferece.

\title{
4 ESTUDO DE CASO: GRUPO DE PRODUTORES VEGANOS (ETAPA 2)
}

O grupo estudado é formado por quatro pequenos empreendimentos que trabalham com produção e venda de alimentos veganos na cidade de Florianópolis, Santa Catarina, desde março de 2015. Salienta-se que produtos veganos são produzidos sem qualquer ingrediente ou subproduto de origem animal em sua composição, bem como ingredientes que possam ter sido testados em animais.

Por meio da observação aberta se deu o primeiro contato com o grupo, momento em que foi possível identificar o cenário no qual estão inseridos e a sua situação atual. Os participantes do grupo explicaram informalmente a história da organização, e principalmente sobre os conceitos seguidos, guiados pelas premissas ético animal do veganismo. Foram observados pontos referentes aos produtos, como os tipos oferecidos, as embalagens e os rótulos e o atendimento e a dinâmica dos integrantes do grupo. O principal ponto observado foi o atendimento diferenciado, em que os participantes da organização além da venda dos produtos, oferecem oportunidade de troca de 
experiências com o público, ao repassar informações sobre o estilo de vida vegano, receitas e curiosidades.

No passo seguinte foram realizadas entrevistas individuais com os quatro representantes do grupo social para obter uma visão particular de cada um deles, sua estrutura organizacional, os fatores humanos e os produtos ofertados. O resultado das entrevistas é apresentado de forma sintetizada a seguir.

Figura 2 - Grupo de produtos veganos de Florianópolis/SC.

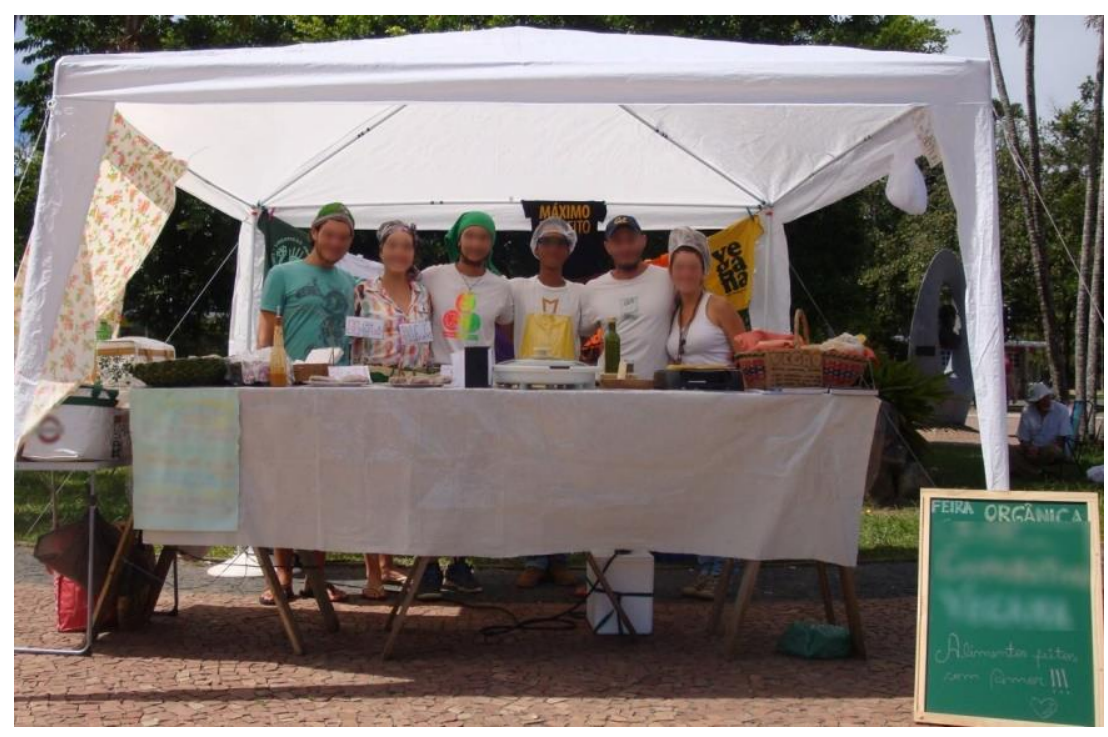

Fonte: Cedido pelos entrevistados (2017).

A formação do grupo se deu para que o mesmo pudesse participar de uma feira agroecológica que acontece em ambiente universitário na cidade onde está inserido. Até então, a feira não contava com expositores veganos, o que resultou em certa resistência por parte dos organizadores no início. Esses produtores decidiram se associar de modo a reunirem mais força em sua representação. A participação nessa feira agroecológica é, hoje, a principal atividade do grupo, ocorrendo semanalmente às quartas-feiras.

Hoje, as quatro representações de empreendimentos atuam de forma linear, de igual para igual, sem hierarquias. O formato em que trabalham e se relacionam se enquadra nas premissas do cooperativismo e economia solidária, em que todos atuam de forma ativa, atendendo a autogestão, de forma que a tomada de decisões em nome do grupo é feita em reuniões entre todos 
os associados e as decisões são por consenso e apenas se todos estiverem de acordo, os assuntos em questão são levados adiante. Os integrantes colaboram uns com os outros e repassam informações sobre técnicas e produtos, de modo a aprimorar a qualidade dos produtos ofertados. Tanto na organização quanto durante as atividades do grupo, as funções são divididas de acordo com as habilidades e preferências de cada associado. Se um membro tem habilidade e conhecimento na área gráfica, geralmente ficará responsável pela criação das artes de panfletos e mídias digitais, outros ficam responsáveis pelo transporte e montagem da estrutura nas feiras e outrem realizam o atendimento ao público.

Figura 3 - Estrutura produtiva do grupo de produtores.
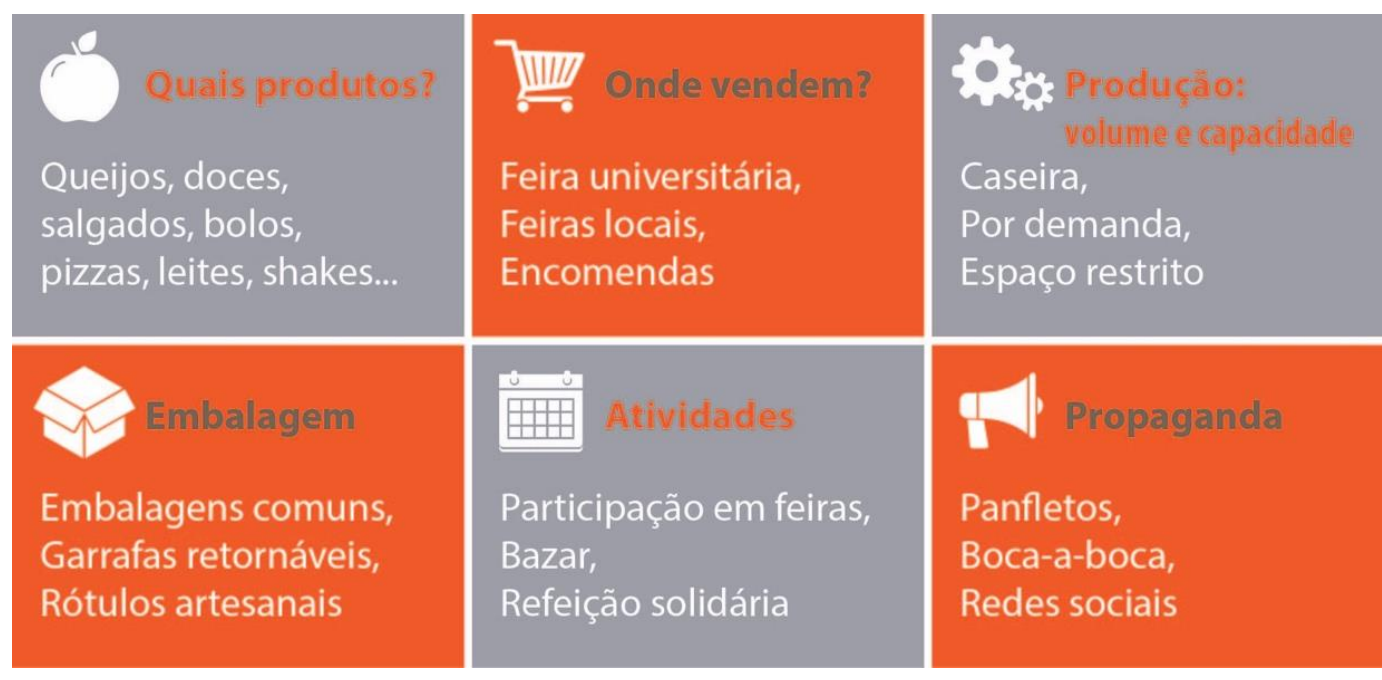

Fonte: Elaborado pelos autores.

Na figura 3 está representada a estrutura produtiva do grupo social analisado, com os seguintes destaques: produtos, ponto de venda, produção, embalagem, atividades e meios de divulgação. Dentre os quatro empreendimentos associados, são ofertados diversos tipos de produtos veganos, todos artesanais e produzidos apenas com recursos vegetais, tais como queijos e leites vegetais, hambúrgueres, pizzas, salgados, bolos, pães, doces e shakes, além de camisetas e livros sobre o veganismo. No tópico a seguir são apresentadas as informações levantadas no diagnóstico preliminar. 
Marco Antonio Weiss, Luiz Fernando Gonçalves de Figueiredo, Eugenio Andrés Díaz Merino, Giselle Schmidt Alves Díaz Merino

\section{RESULTADOS E DISCUSSÃO}

Diante do cenário apresentado, foi possível analisar as potencialidades e fragilidades do grupo estudado, sob o foco da gestão de design, de modo a interferir e colaborar interna e externamente ao sistema ao qual o grupo está envolvido.

Como pontos fortes do empreendimento, elencaram-se três principais: o diferencial dos produtos que proporcionam uma alimentação mais saudável e consciente, uma vez que além de veganos, são produzidos de forma artesanal, utilizam o máximo de ingredientes orgânicos e não fazem uso de produtos refinados, tais quais farinha, açúcar ou sal, bem como não utilizam transgênicos e frituras; as tarefas no grupo são divididas de acordo com as habilidades de cada membro, tornando as ações mais eficientes e as sobrecargas desnecessárias e por último, o atendimento que possibilita um ambiente acolhedor, troca de informações e experiências.

Com relação às fragilidades, constataram-se diversos fatores que podem ser trabalhados, tais quais: o grupo ainda atua de maneira informal, ou seja, não possui registro nos órgãos reguladores; possui uma identidade visual feita de forma amadora; o conhecimento dos princípios fundamentais do grupo ainda se dá de forma empírica, o que dificulta a adesão de novos membros; a maior parte dos produtos oferecidos não possui embalagens identificadas; como a produção é caseira, encontram dificuldades em produzir e armazenar maiores quantidades de produtos; além de não possuir um estatuto, missão, visão e valores bem definidos.

Figura 4 - Estrutura da pesquisa.

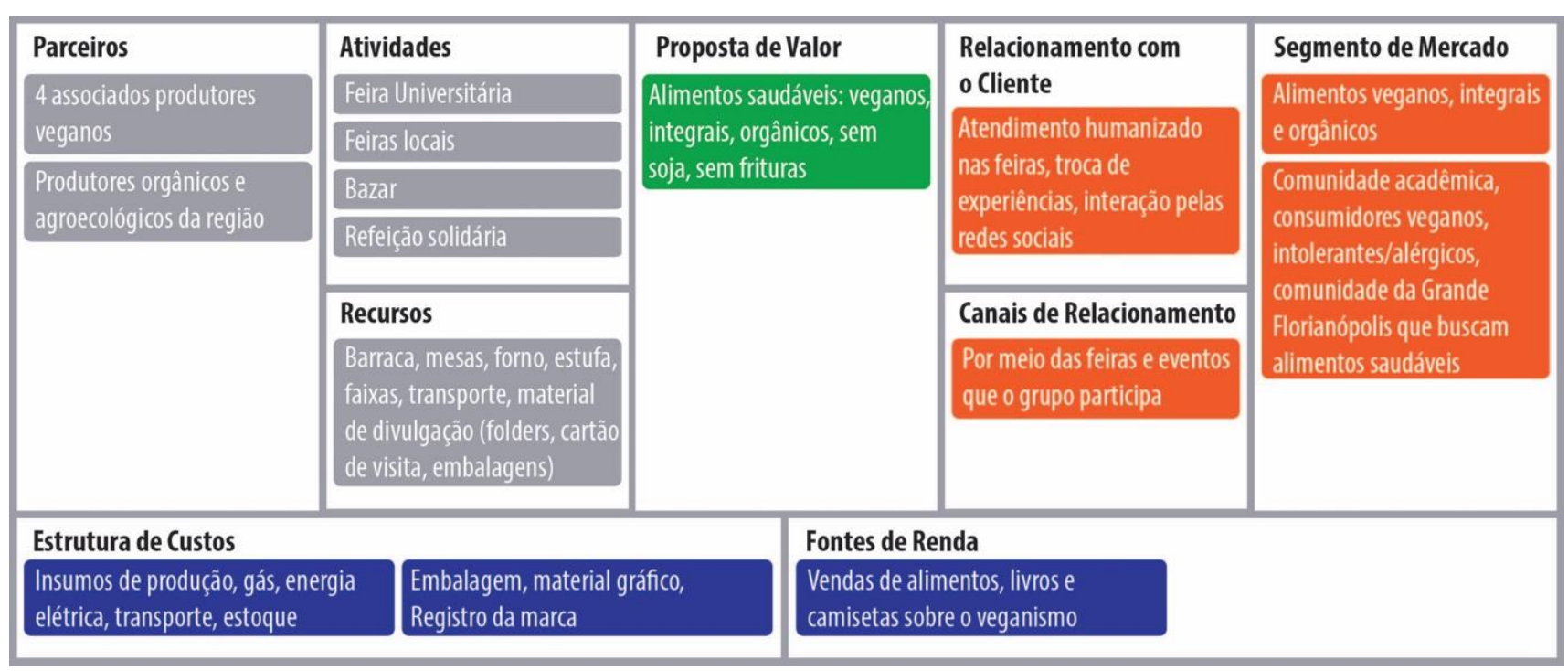

Fonte: Elaborado pelos autores. 
A figura 4 apresenta a ferramenta de plano de negócios Canvas aplicada para representar o modelo de negócio do grupo de produtores veganos analisado. De acordo com Finocchio Júnior (2013), o plano de negócios Canvas segue um modelo mental aplicado como uma ferramenta preliminar que dará a forma do projeto, podendo ser a base para um posterior plano de projeto transcrito formalmente. O Canvas elaborado desse empreendimento condensa as informações levantadas para auxiliar nas diretrizes para o desenvolvimento das atividades presentes e futuras.

A economia solidária, como apresentado, representa uma nova forma de produzir, vender, comprar e trocar o que é preciso para viver, buscando um desenvolvimento sustentável, cooperativo e não mais competitivo. O grupo se fortalece com a cooperação, trabalhando para bem coletivo e para o próprio bem. Dessa forma, mais do que visar o lucro, o grupo analisado valoriza a expansão do veganismo e do desenvolvimento sustentável por meio de um atendimento humanizado e acolhedor, proporcionando ao público um ponto de encontro e troca de conhecimentos.

\section{CONSIDERAÇÕES FINAIS}

Com base na fundamentação teórica, pode-se abranger o conhecimento acerca dos temas inovação social, cooperativismo, economia solidária e gestão de design, o que possibilitou estabelecer a conexão entre eles, bem como com a etapa aplicada do estudo de caso e, ainda, respaldar a proposta desta pesquisa.

Com o propósito de solucionar problemas e atender às necessidades das pessoas, a atividade do designer visa melhorar a qualidade de vida. "O design junto de sua gestão tem a preocupação de comunicar e criar condições para que o seu público entenda sua mensagem e perceba seus benefícios, por meio de estratégias e estudos multidisciplinares" (PRETO; ALANO, 2013, p. 12). Assim, sob uma abordagem da gestão de design, buscou-se identificar oportunidades a serem trabalhadas junto a um grupo de produtores veganos da cidade de Florianópolis/SC, os quais atuam de forma colaborativa e dentro das premissas da economia solidária. 
Com a realização desta pesquisa ${ }^{2}$ percebeu-se que estudar empreendimentos que atuam em consonância com a economia solidária amplia a concepção sobre relações sociais e de trabalho, percebendo que existe alternativa ao modelo de competição ao qual estamos acostumados e, nesse caso, essa alternativa busca aliar o retorno financeiro com a solidariedade, cooperação e valorização do ser humano. Na etapa 2 deste artigo, foi possível identificar os principais aspectos da economia solidária apresentados no referencial teórico da etapa 1. Quanto à autogestão, o grupo atua de forma linear, sem hierarquias e a tomada de decisões é feita de forma democrática e consensual, por meio de reuniões com todos os integrantes, os assuntos a serem tratados são colocados em pauta e todos os associados podem opinar e, apenas se todos estiverem de acordo os assuntos em questão são levados adiante. A cooperação, a solidariedade e o respeito são a base da relação entre os associados, todos estão dispostos a contribuir e aprender mutuamente, tendo sempre uma troca de saberes e experiências. Não havendo competição, os integrantes têm mais segurança e autonomia na realização de suas atividades, o que contribui para o bem coletivo.

Atendendo ao objetivo de desenvolver um diagnóstico preliminar da atual situação do grupo, como resultado, gerou-se um levantamento de pontos fortes e fragilidades que podem ser abordados, na atuação da gestão de design, de modo a auxiliar os pequenos produtores veganos a melhor desenvolverem suas atividades e a oferta de seus produtos. Dessa forma, enriquece-se o trabalho e fortalecem os empreendimentos que promovem um estilo de vida mais saudável, ético e sustentável, e representam uma fonte de renda alternativa ao modo convencional de configuração econômica, gerando assim, uma inovação social.

À vista disso, identificaram-se pontos em que a gestão de design pode contribuir buscando o reconhecimento desses pequenos empreendimentos de economia solidária no planejamento e execução de suas atividades, de modo que estas estejam alinhadas com os objetivos do grupo e sejam eficientes na transmissão dos conceitos defendidos por seus membros, no caso do grupo social estudado, o foco orientador está, mais que na venda de alimentos, mas na disseminação do conhecimento sobre o veganismo, bem como a ética de desenvolvimento sustentável a ele atrelado.

\footnotetext{
${ }^{2}$ O presente trabalho foi realizado com apoio da Coordenação de Aperfeiçoamento de Pessoal de Nível Superior - Brasil (CAPES) - Código de Financiamento 001.
} 
Com base nos pontos levantados no diagnóstico preliminar, identificaram-se ações de melhoria no grupo de produtores veganos a partir da aproximação do design, tais como a reformulação e elaboração da marca e identidade visual do grupo, o que facilitará o desenvolvimento de etiquetas para identificação dos produtos vendidos, fortalecendo, assim, a comunicação interna e externa da marca. Ainda quanto à identidade visual, não se identificou a necessidade de se desenvolver embalagens exclusivas, em uma primeira intervenção seriam desenvolvidas etiquetas para identificação dos produtos, contendo informações essenciais sobre o produto e seus produtores. Outra ação identificada como importante é a elaboração de um estatuto da organização, definindo itens como visão, missão e valores do grupo, diretrizes para adesão de novos membros, histórico e objetivos, de modo a consolidar e formalizar os conceitos, ideais e metas defendidos pelo grupo.

A partir disso será possível definir objetivos e interesses, adequados à realidade organizacional, de modo a potencializar os benefícios da ação do design no contexto da economia solidária, agregando o conhecimento acadêmico e tecnológico do designer ao saber empírico e propósitos do grupo de produtores. Esse diagnóstico preliminar servirá de base para a continuação desse estudo, em que percebeu-se a viabilidade de elaboração de um plano estratégico de gestão de design, definindo objetivos e ações a serem desenvolvidas a curto, médio e longo prazo com o grupo de produtores veganos, dentre as ações identificadas destacam-se o desenvolvimento de uma identidade visual, etiquetas para os produtos e estatuto dos associados.

\section{REFERÊNCIAS}

ANDA. Agência de Notícias de Direitos Animais. Seis fatos que revelam o avanço do veganismo no mundo. Disponível em: http://www.anda.jor.br/23/05/2016/seis-fatos-que-revelam-o-avanco-doveganismo-no-mundo. Acesso em: 19 mar. 2019.

ARCANJO, Rodrigo da Silva; MARQUES, Jódiney Benedito. O cooperativismo popular na perspectiva da economia solidária como instrumento de inclusão social. In: SIMPÓSIO DE EXCELÊNCIA EM GESTÃO E TECNOLOGIA, 9., 2012, Resende. Anais [...]. Resende: AEDB, 2012. p. 1-15. Disponível em: http://www.aedb.br/wp-content/uploads/2015/04/23316315.pdf. Acesso em: 19 mar. 2019.

CSI. Center for Social Innovation. Defining Social Innovation. [2017]. Disponível em: https://www.gsb.stanford.edu/faculty-research/centers-initiatives/csi/defining-social-innovation. Acesso em: 19 mar. 2019. 
FIALHO, Francisco A. P.; BRAVIANO, Gilson; SANTOS, Neri dos. Métodos e técnicas em ergonomia. Florianópolis: Edição dos autores, 2005.

FINOCCHIO JÚNIOR, José. Project model Canvas: gerenciamento de projetos sem burocracia. Rio de Janeiro, Elsevier, 2013.

GAIGER, Luiz Inácio. A economia solidária e a revitalização do paradigma cooperativo. Revista Brasileira de Ciências Sociais, São Paulo, v. 28, n. 82, p.211-228, jun. 2013. Disponível em: https://www.redalyc.org/articulo.oa?id=10727637017. Acesso em: 19 mar. 2019.

GIL, Antônio Carlos. Como elaborar projetos de pesquisa. 5. Ed. São Paulo: Atlas, 2010.

LAURO, Aline Bertolini de. Abordagem sistêmica e gestão de design na formação de uma rede integradora de serviços. 2014. 119 f. Dissertação (Mestrado) - Curso de Programa de Pósgraduação em Design e Expressão Gráfica, Centro de Comunicação e Expressão, Universidade Federal de Santa Catarina, Florianópolis, 2014. Disponível em:

https://repositorio.ufsc.br/xmlui/handle/123456789/129498. Acesso em: 19 mar. 2019.

MANZINI, Ezio. Design para a inovação social e sustentabilidade: Comunidades criativas, organizações colaborativas e novas redes projetivas. Rio de Janeiro: E-papers, 2008.

MARTINS, Rosane Fonseca de Fonseca; MERINO, Eugenio Andrés Diaz. A gestão de design como estratégia organizacional. Londrina: Eduel; Rio de Janeiro: Rio Books, 2011.

MAURER, Angela Maria. As dimensões de inovação social em empreendimentos econômicos solidários do setor de artesanato gaúcho. 2011. 191 f. Dissertação (Mestrado) - Curso de Administração, Escola de Administração, Universidade Federal do Rio Grande do Sul, Porto Alegre, 2011. Disponível em: https://lume.ufrgs.br/handle/10183/35828. Acesso em: 19 mar. 2019.

MOTTA, Fabíola da Silva Nader (Org.). Agenda Institucional do Cooperativismo. Brasília: Sistema OCB, 2017. Disponível em: http://www.ocb.org.br/arquivos/Publicacoes/agenda_institucional.pdf. Acesso em: 08 jun. 2017.

MOZOTA, Brigitte Borja de. Gestão do design: usando o design para construir valor de marca e inovação corporativa. Porto Alegre: Bookman, 2011.

MOULAERT, Fran; MARTINELLI, Flavia; SWYNGEDOUW, Erik; GONZÁLEZ, Sara. Towards alternative model(s) of local local innovation. Urban Studies, [s.I.], v. 42, n. 11, p.1969-1990, out. 2005. Disponível em: https://journals.sagepub.com/doi/abs/10.1080/00420980500279893. Acesso em: 19 mar. 2019.

OCB. Organização das Cooperativas Brasileiras. O que é cooperativismo. [2017]. Disponível em: https://www.ocb.org.br/o-que-e-cooperativismo. Acesso em: 19 mar. 2019. 
PRESTES, Maíra Gomes; FIGUEIREDO, Luiz Fernando Gonçalves. Novas perspectivas para o design: designers como agentes de desenvolvimento local. Design e Tecnologia, [s.I.], v. 2, n. 3, p.38-45, dez. 2011. Disponível em: https://www.ufrgs.br/det/index.php/det/article/view/61. Acesso em: 19 mar. 2019.

PRETO, Seila Cibele Sitta; ALANO, Agda Bernardete. A gestão de design social e sustentabilidade de empreendimentos econômicos solidários. Projetica, [s.I.], v. 4, n. 1, p.9-22, jan./jun. 2013. Disponível em: http://www.uel.br/revistas/uel/index.php/projetica/article/view/15509. Acesso em: 19 mar. 2019.

ORSIOLLI, Thálita Anny Estefanuto; NOBRE, Farley Simon. Empreendedorismo sustentável e stakeholders fornecedores: criação de valores para o desenvolvimento sustentável. Revista de administração contemporânea, Curitiba, v. 20, n. 4, p. 502-523, ago. 2016. Disponível em: http://www.scielo.br/scielo.php?script=sci_arttext\&pid=S141565552016000400502\&lng=pt\&nrm=iso. Acesso em: 19 mar. 2019.

OSTERWALDER, Alexander. Business model generation: inovação em modelos de negócios: um manual para visionários, inovadores e revolucionários. Rio de Janeiro: Alta Books, 2011.

SILVA, Diego Borges da; TRISKA, Ricardo; MERINO, Eugenio Andres Diaz; MERINO, Giselle Schmidt Alves Díaz. Gestão de Design: diagnóstico preliminar sobre a Casa da Alfândega. Revista D.: design, educação, sociedade e sustentabilidade, Porto Alegre, v. 9, n. 1, p.3-22, 2017. Disponível em: https://seer.uniritter.edu.br/index.php?journal=revistadesign\&page=article\&op=view\&path\%5B\%5 $\mathrm{D}=1442$. Acesso em: 19 mar. 2019.

SILVA, Luiz Antônio Coêlho da; FARIAS, João da Silva. A autogestão e a incubadora solidária da UFCG: estudo de campo com o grupo de arte em vidro e a emancipação de seus atores sociais. Revista Saúde e Ciência, [s.I.], v. 3, n. 3, p. 118-136, set-dez, 2014. Disponível em: http://www.ufcg.edu.br/revistasaudeeciencia/index.php/RSC-UFCG/article/view/179. Acesso em: 19 mar. 2019.

SINGER, Paul. Introdução à economia solidária. São Paulo: Editora Fundação Perseu Abramo, 2002.

SOARES, Maria Carolina Beirão. As possibilidades de articulação entre inovação e empreendedorismo e as economias nos territórios de baixa densidade: o caso das Lameiras. 2014. 146 f. Dissertação (Mestrado) - Curso de Intervenção Social, Inovação e Empreendedorismo, Faculdade de Economia, Universidade de Coimbra, Coimbra, 2014. Disponível em: https://estudogeral.sib.uc.pt/handle/10316/27587. Acesso em: 19 mar. 2019.

SOCIEDADE VEGANA. Textos fundamentais: Veganismo. 2011. Disponível em: http://sociedadevegana.org/textos-fundamentais/veganismo/. Acesso em: 19 mar. 2019. 